\title{
A RETÓRICA ENTRE O DISCURSO E A COGNIÇÃO: A MESCLAGEM CONCEPTUAL COMO ESTRATÉGIA ARGUMENTATIVA
}

\author{
RHETORIC BETWEEN DISCOURSE AND COGNITION: \\ CONCEPTUAL BLENDING AS AN ARGUMENTATIVE STRATEGY
}

\author{
Diogo Oliveira Ramires Pinheiro \\ Universidade Federal da Fronteira Sul \\ Luciano Carvalho do Nascimento \\ Universidade Federal da Fronteira Sul \\ Cmdo. Exército - $5^{\mathrm{a}} \mathrm{RM}$
}

\section{Resumo}

Este trabalho interdisciplinar - que conjuga a Análise do Discurso de linha francesa (AD) e a Linguística Cognitiva (LC) - analisa três textos argumentativos consideravelmente distintos a fim de identificar uma estratégia comum de persuasão. Primeiramente, apontamos a relevância do conceito de ficcionalização - desenvolvido por autores como Anne Reboul e Emilia Mendes-Lopes - para uma teoria da argumentação. Mostramos também que a relação entre ficcionalização e argumentação reside no fato de que a primeira explicita a organização do discurso em função do logos aristotélico. Em um segundo momento, defendemos, à luz da LC, que a relação entre ficcionalização e logos é motivada pelo processo cognitivo de mesclagem conceptual.

Palavras-chave: Argumentação. Ficcionalização. Logos. Mesclagem conceptual.

\begin{abstract}
This interdisciplinary paper, which combines French Discourse Analysis (DA) and Cognitive Linguistics (CL), analyses three considerably different argumentative texts in order to identify a common persuasion strategy among them. Firstly, we point to the relevance of the notion of fictionalization - developed by authors such as Anne Reboul and Emilia Mendes-Lopes - for a theory of argumentation. We also show that this relationship lies on the fact that fictionalization makes a logos-based argumentation more visible to the hearer/reader. Secondly, we argue, under CL framework, that the relationship between fictionalization and logos is motivated by the cognitive process known as conceptual blending.
\end{abstract}

Keywords: Argumentation. Ficcionalization. Logos. Conceptual blending.

\section{PRIMEIRAS PALAVRAS}

O que torna um texto argumentativo mais eficaz que outro? Que mecanismos distinguem a argumentação eficaz daquela que não consegue atingir seus objetivos? Evidentemente, muitas são as respostas possíveis - e corretas - para essa pergunta. Neste artigo, argumentamos que uma dessas respostas reside na estratégia linguístico- 
discursiva que tem sido chamada de ficcionalização ou ficcionalidade ${ }^{1}$ (REBOUL, 1992; MENDES-LOPES, 2004; MENDES-LOPES, 2005, respectivamente). Definido como “mecanismo de produção da ficção, ou de ativação da ficção" (MENDESLOPES, 2004, p. 117), esse processo tem recebido relativamente pouco espaço na seara dos estudos do discurso. Neste trabalho, buscamos demonstrar sua relevância para o campo da Retórica, ao mesmo tempo em que procuramos desvelar os processos cognitivos a ele subjacentes.

Para isso, este trabalho se desenvolve a partir da análise de três textos argumentativos bastante diferentes entre si. O primeiro foi publicado no blog A neurocientista de plantão, de autoria da pesquisadora Suzana Herculano-Houzel, no dia 15 de julho de 2009. O segundo - parte de uma campanha publicitária lançada em 22 de junho de 2009 por uma companhia farmacêutica norte-americana - é um cartaz que se propõe a divulgar e incentivar os testes de HIV. O terceiro, por fim, é formado por uma sequência de três fotos de um dispenser de banheiro criado em junho de 2008, pela agência de publicidade Saatchi \& Saatchi, para a ONG ambientalista World Wild Foundation.

Marcadamente interdisciplinar, já que se situa na fronteira entre a $\mathrm{AD}$ e a $\mathrm{LC}$, este estudo se divide em duas partes. Na seção 2, inserida no quadro teórico da $\mathrm{AD}$, procedemos a uma análise dos três textos selecionados. Nesse momento, sustentamos a seguinte hipótese: alguns textos, especialmente eficientes do ponto de vista retórico, são marcados por um processo de ficcionalização que leva os argumentos a mimetizarem a estrutura lógica, ou quase-lógica (PERELMAN; OLBRECHTS-TYTECA, 1996), da argumentação, organizando-a segundo o logos aristotélico (ARISTÓTELES, "Retórica"). Pudemos detectar, dessa forma, a existência de uma correlação entre ficcionalização e logos, de um lado, e incremento da eficácia argumentativa, de outro.

Tal correlação, no entanto, satisfaz apenas o plano descritivo, mas não o plano explicativo: aponta-se um vínculo entre ficcionalização/logos e poder de convencimento, mas não se explica a motivação que subjaz a esse vínculo. Nesse sentido, a pergunta que permanece é a seguinte: por que, exatamente, o discurso ficcional deveria ser mais persuasivo que o não-ficcional? Que propriedade desse tipo de discurso o torna tão especialmente eficiente no que tange ao projeto de convicção?

Uma explicação é oferecida na segunda parte deste trabalho, na qual os três textos argumentativos são retomados e analisados, dessa vez, à luz da LC. Nesse momento, mostramos que a relação entre discurso ficcional, de um lado, e eficácia argumentativa, de outro, envolve o mecanismo cognitivo conhecido como mesclagem conceptual (GRADY; OAKLEY; COULSON, 1999; FAUCONNIER; TURNER, 2002; entre outros). Mais especificamente, argumentaremos que a compressão conceptual promovida pela mesclagem é a responsável direta pelo incremento do poder argumentativo dos textos analisados.

Este estudo, em suma, apresenta e defende duas hipóteses. A primeira, de caráter descritivo e eminentemente discursiva, sustenta que o processo de ficcionalização

\footnotetext{
${ }^{1} \mathrm{Na}$ literatura especializada, os dois termos são usados indistintamente. Neste trabalho, empregamos "ficcionalização" para tratar de processos e/ou mecanismos discursivos, e "ficcionalidade" para aludir ao caráter ficcional de alguns textos.
} 
incrementa o poder de convicção de um texto. A segunda, de caráter explicativo e eminentemente cognitivista, sustenta que esse incremento é resultado da compressão conceptual promovida pelo processo de mesclagem.

Fica claro, assim, que as perspectivas discursiva e cognitivista não são independentes. Embora os caminhos se bifurquem, eles também se encontram: um olhar ajuda a esclarecer o outro, e a apreensão do objeto se torna mais completa quando se beneficia da imagem construída a partir de dois pontos de vista. Neste artigo, pretendemos dar um exemplo concreto de como esses dois enfoques - o discursivo e o cognitivo - se complementam, permitindo uma compreensão mais profunda dos mecanismos que tornam um texto argumentativo verdadeiramente eficaz.

\section{A ABORDAGEM DISCURSIVA}

A disposição aristotélica de formalizar uma técnica que possibilitasse encontrar, em cada caso, o argumento mais eficaz elevou a Retórica da condição de exercício lúdico para os sofistas - a de instrumento pragmático - para oradores, em geral. Ela era muito útil, por exemplo, nas contendas jurídicas por terras e nos comentários públicos em louvor a figuras eminentes (REBOUL, 2004). Vários conceitos desenvolvidos à época colaboram, ainda hoje, para a descrição dos mecanismos da argumentação.

Logos, ethos e pathos são alguns deles. Segundo Aristóteles, essas são as três "provas”² fornecidas pelo discurso. Ele apresenta tais provas como procedimentos para convencer e persuadir, referindo-se, então, a textos orais. Posteriormente, outros teóricos estenderam tais considerações a textos escritos (REBOUL, 2004; PERELMAN; OLBRECHTS-TYTECA, 1996; AMOSSY, 2005). Logos é o poder demonstrativo imanente às palavras, ao discurso em si; ethos, a imagem de confiabilidade que o orador inspira; pathos é a atitude responsiva (ainda que proativa) ao lugar discursivo em que os ouvintes/ leitores estão colocados, quer dizer, ao seu comportamento, presumido ou atestado. Neste artigo, interessa-nos especialmente o primeiro desses procedimentos, 0 logos.

Os argumentos “lógicos” evocam os aspectos mais "racionais” ou "razoáveis" das questões, portanto, levam a uma conclusão. Mais até: conduzem a uma conclusão necessária, irrefutável. Aristóteles discorre sobre a estrutura dos argumentos lógicos e nos apresenta a matriz estrutural desse procedimento persuasivo - o silogismo: partindo-se de duas premissas verdadeiras e inquestionáveis, chega-se a uma conclusão inequívoca, "lógica”.

Entretanto, não raro, o que se nos apresenta como lógico é, na realidade, uma "ficção" 3 . Muitas vezes os argumentos "se fundamentam na estrutura do real" (PERELMAN; OLBRECHTS-TYTECA, 1996, p. 210), e a estrutura lógica formal é utilizada como molde para uma argumentação apoiada no senso comum e na experiência - não na comprovação científica, nem na demonstração dos fenômenos. Esse, aliás, é um fator

\footnotetext{
${ }^{2}$ Entenda-se "prova" como argumento (ARISTÓTELES, "Retórica"), no sentido de mecanismo ou sustentáculo sobre o qual se apoia o plano persuasivo.

${ }^{3}$ O termo "ficção" é entendido, nos termos de Mendes-Lopes (2005, p. 32), como "a simulação de uma situação possível, de ordem semiolinguística, discursiva [...], psicossocial ou espacial”.
} 
que endossa a visão interdisciplinar: o traço empírico da convicção por "argumentos que se fundamentam na estrutura do real", valendo-se de uma aproximação com "modos de raciocínio incontestados", de onde "tiram sua força persuasiva" (PERELMAN; OLBRECHTS-TYTECA, 1996, p. 210).

Um desses “modos de raciocínio incontestados" é a dedução, de natureza intrinsecamente silogística. O método dedutivo implica uma relação de causalidade, bastante recorrente na articulação dos projetos persuasivos. ${ }^{4}$ Estruturas como "X porque Y”, “já que X, então Y”, "se X, então Y” são fórmulas de representação da causalidade na organização lógica argumentativa (CHARAUDEAU, 2008).

No entanto, a conclusão a que se chega por meio de premissas questionáveis não é lógica, mas "quase lógica". Isso acontece, por exemplo, quando as premissas se sustentam em verossimilhanças - o que poderia ser real, ou "tudo aquilo em que a confiança é presumida” (REBOUL, 2004) - ou na ficcionalização, conforme MendesLopes (2005). Esse mecanismo é condição natural da linguagem, dado o caráter representativo, inerente a tal faculdade humana. Nos termos de Mendes-Lopes (2005), a ficcionalidade pode ser constitutiva ou colaborativa, conforme esteja mais ou menos enraizada nos mecanismos linguísticos stricto sensu. Assim, categorias gramaticais como o tempo (passado ou futuro) são compreendidas por meio da ficcionalidade constitutiva, imanente à língua; por seu turno, reconstruções de eventos e metáforas, em geral, estão relacionadas à ficcionalidade colaborativa (idem, ibidem). ${ }^{5}$

Dessa forma, infere-se que, se a argumentação lógica é, para Aristóteles, persuasiva por si só, já a persuasão por meio de "argumentos que se fundamentam na estrutura do real" será, para Perelman e Olbrechts-Tyteca, tanto mais eficaz quanto mais suas premissas se apoiarem no senso comum. Esse grau de aderência será maior ou menor conforme as associações de ideias, feitas durante o processo de convencimento, estejam mais ou menos ancoradas em modos de raciocínio reconhecidamente válidos.

Vejamos, na análise dos textos selecionados, como isso acontece na prática.

\subsection{Abordagem discursiva dos textos selecionados: reconstruindo ficcionalidade e causalidade}

\subsubsection{Abordagem discursiva do Texto 1}

E depois, tem a versão light da imagem-suficientemente-impactantepara-fazer-mudar-de-ideia. Minha estagiária Bianca lembrou esta

\footnotetext{
${ }^{4}$ Segundo Charaudeau (2008), essa é a relação basal em se tratando de argumentação. Ele apresenta diferentes configurações frasais - de ordem gramatical, textual e discursiva - em que tal relação se inscreve, caracterizando o que o teórico francês chamou "modo de organização argumentativa do discurso".

${ }^{5}$ Essa identificação do conceito de ficcionalidade com os procedimentos metafóricos aproxima a perspectiva discursiva do fenômeno - chamado por Charaudeau (2008) de "semiotização do mundo" daquela adotada pela LC, na medida em que as relações interdominiais (como a metáfora e a mescla; cf., por exemplo, Lakoff e Johnson (1980; 1999) e Fauconnier e Turner (2002)) e as intradominiais (como a metonímia; cf., por exemplo, Croft (1993)) são objeto constante de estudos cognitivistas.
} 
semana da minha estratégia com os alunos da Psicologia para que eles não descessem ao Anatômico, onde têm aulas práticas, mascando chiclete, comendo, bebendo água ou com bala na boca. Saca só a lógica: as peças anatômicas, mesmo as plastinadas e super bem cuidadas, têm fungos na superfície, e esses fungos passeiam pelo ar e são absorvidos pela bala, chiclete ou água na sua boca. O mesmo vale para as peças fixadas, que exalam formol. Portanto, se fungos $e$ formol são absorvidos pelo chiclete, descer para a aula prática mascando chiclete é o mesmo que... lamber as peças e os cadáveres da aula. Você faria isso?

(Disponível em: http://www.suzanaherculanohouzel.com. Acesso em: 27/11/09)

Nesse texto (cuja versão na íntegra se encontra em anexo), a neurocientista Suzana Herculano-Houzel deseja convencer seus alunos a não irem ao laboratório comendo ou portando alimentos. Para tal, ela busca, deliberadamente, construir uma "imagemsuficientemente-impactante-para-fazer-mudar-de-ideia”. Fica bastante claro, nessa passagem, o caráter argumentativo do texto.

Nota-se, em sua exposição, que o recurso ao senso comum (ao topos) é evidente. Tendo como fundo o que um cadáver tem de repulsivo na cultura ocidental, a cientista vai, pouco a pouco - valendo-se de nosso conhecimento de mundo acerca das propriedades mais gerais dos microorganismos -, dando forma ao argumento final: "Comer no laboratório é lamber cadáveres”. Atente-se para o fato de haver algo de equívoco na argumentação da professora: nenhum dos alunos hipoteticamente presentes no laboratório irá, de fato, lamber os cadáveres - essa imagem é absolutamente ficcional. Entretanto, isso não é ressaltado, estabelecendo-se um "universo de crença compartilhado” (CHARAUDEAU, 2008).

Engendrando situações possíveis, a ficcionalização se constitui fator preponderante em todo esse processo persuasivo, uma vez que, sem ser falaciosa, a argumentação da professora tampouco é lógica, mas se vale das experiências acumuladas por seus alunos para, repetindo o modelo silogístico, articular ideias de maneira a criar uma realidade verossímil, representada definitivamente por uma "imagem-suficientemente-impactantepara-fazer-mudar-de-ideia”: "lamber cadáveres”. E ninguém mais entra no laboratório portando gêneros alimentícios.

Esquematicamente, o procedimento persuasivo que acabamos de descrever pode ser representado por meio da fórmula "se X, então Y”. Esse mecanismo evidencia a relação causa vs. consequência existente entre ideias apostas em vínculo de implicação.

QUADRO 1. Topos “Cadáveres são repulsivos”

[Topos: “Cadáveres são repulsivos.”]

SE “Comer no laboratório é lamber cadáveres.” (imagem ficcional, argumento utilizado) ENTÃO “Não comerei no laboratório.” (conclusão quase-lógica desejada) 
A representação acima, que acreditamos bastante clara, mostra como a ficcionalidade confere à argumentação uma lógica intrínseca e autoevidente, da qual emerge seu poder de conviç̧ão.

\subsubsection{Abordagem discursiva do Texto 2}

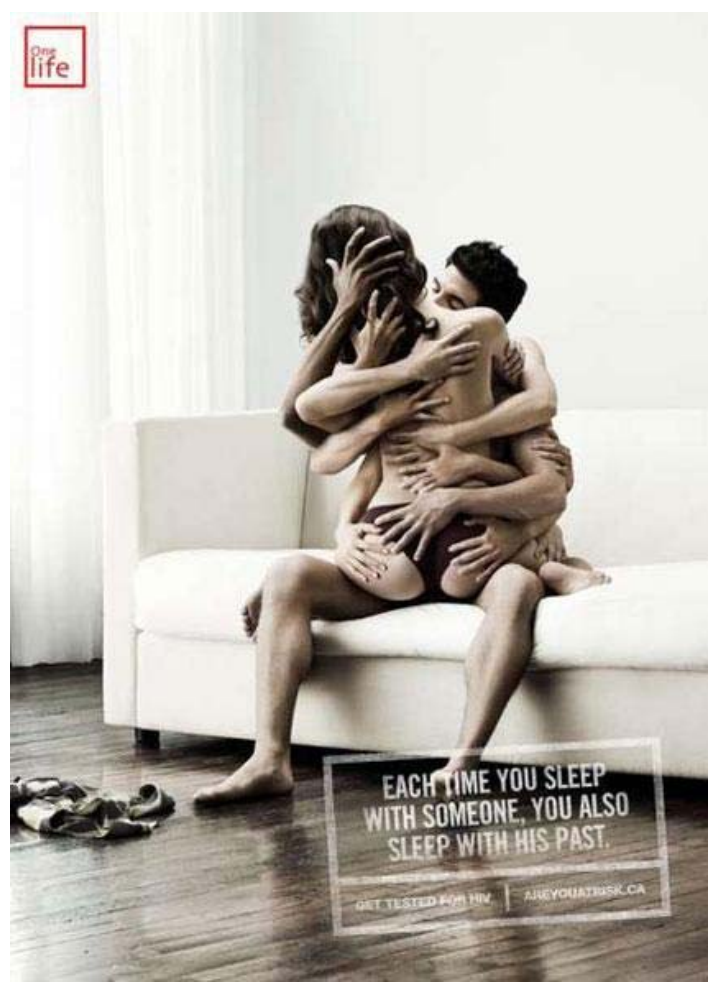

FIGURA 1. Faça o teste de HIV

O segundo texto - parte de uma campanha publicitária lançada em 22 de junho de 2009 por uma companhia farmacêutica norte-americana - se propõe a divulgar e promover o teste para detecção do vírus HIV. Sugere-se, por imagem, que um casal está mantendo relações sexuais, e, em primeiro plano, veem-se vários pares de braços nas costas da moça. Ao par desse texto não-verbal, lê-se: “A cada vez que dorme com alguém, você também dorme com o passado dessa pessoa. Faça o teste de HIV.”6

Partindo do elemento não-verbal, já é bastante claro o recurso à ficção. Há apenas duas pessoas na cena - nada real justificaria a existência de tantos braços. Entretanto, passando para a leitura atenta do texto verbal, percebe-se que, assim como no caso anterior, a ficcionalidade é fator preponderante na argumentação.

Trata-se de uma campanha cujo caráter pedagógico e preventivo se coaduna com o objetivo de convencer as pessoas a se submeterem ao teste para detecção do HIV. O enunciador evoca o conhecimento de mundo do leitor, e supõe que este saiba que: a) esse vírus é o agente causador da AIDS; b) a AIDS é uma doença letal, cuja cura ainda

\footnotetext{
${ }^{6}$ Tradução nossa. O texto original em inglês é: "Each time you sleep with someone, you also sleep with his past. Get tested for HIV."
} 
não se descobriu; c) uma das principais formas de contágio por HIV é o contato sexual com pessoas infectadas.

Tudo isso faz parte do senso comum, quer dizer, compõe um topos. Todavia, nesse caso particular, a argumentação articula conhecimentos ainda mais enraizados na nossa mente. Na verdade, um conjunto de "informações" que se ligam à nossa própria herança evolutiva: o chamado "instinto de sobrevivência”. Afinal, se é ele que, nos primórdios da espécie, nos levava a fugir diante do perigo iminente, inconscientemente buscando salvaguardar a transferência de nossos genes à posteridade, é ele também que, hoje, nos faz evitar a maioria das situações que atentam à nossa própria vida.

Assim, é importante representar essa primeira estrutura, que está subjacente à "lógica autoevidente” da argumentação empreendida a partir dela.

QUADRO 2. Topos “É necessário sobreviver”

[Topos: “É necessário sobreviver.”]

SE “Algo causar riscos à vida"

ENTÃO "Devo evitar fazê-lo."

A causalidade - apresentada como “dedução condicional” (CHARAUDEAU, 2008) - já se demonstra nessa primeira etapa do processo. Evitar riscos é uma conclusão lógica para quem quer preservar a vida, e a importância dessas atitudes é uma "opinião geralmente aceita” (ARISTÓTELES, “Tópicos”). É justamente por ter esse caráter hegemônico que tal acepção sustenta, como topos, a segunda organização lógica, mais superficial, articuladora mais visível da persuasão.

O fato de qualquer pessoa ser, potencialmente, portadora do vírus HIV é uma ameaça à sobrevivência de todos. Essa noção é tão genérica que abarca, inclusive, individualmente, cada leitor/observador do texto publicitário, e esse é um dos efeitos convincentes desejáveis ${ }^{7}$. A resposta esperada, atestadora da eficácia argumentativa, seria a de o observador acatar a proposta do anunciante e fazer o teste. Tal atitude adviria da crença segundo a qual ele próprio já poderia estar contaminado pelo vírus, exatamente por ser quase impossível reconstituir a história dos relacionamentos sexuais de cada um de seus parceiros anteriores.

Em outras palavras, se é possível a alguém saber de suas próprias relações pregressas, o mesmo não se dá com a história de cada uma dessas pessoas com quem esse alguém se relacionou. Tal dificuldade cresce de forma exponencial, uma vez que todo novo indivíduo integrante da cadeia traria consigo seu próprio inventário de parceiros. Ciente de todas essas possibilidades, o observador preferiria tentar preservar a própria vida lembremo-nos do "instinto de sobrevivência” -, e faria o teste.

Esquematicamente, temos:

\footnotetext{
${ }^{7}$ Afirma-se isso em virtude do fato de que, no texto verbal original, é gramaticalmente marcada a voz passiva, ou seja, é sugestão do enunciador da campanha que o leitor/observador do anúncio se submeta ao teste.
} 
QUADRO 3. Topos “Não devo arriscar minha vida”

[Topos: “Não devo arriscar minha vida”]

SE “Não posso saber com quem já dormi.” (imagem ficcional, argumento utilizado)

ENTÃO “Vou fazer o teste para HIV.” (conclusão quase-lógica desejada)

Ver a si mesmo como uma possível vítima da sugerida promiscuidade de seus parceiros persuade, em tese, o leitor-alvo da propaganda, que, impulsionado por seu instinto de sobrevivência, submeter-se-ia ao teste de HIV. Afinal, é “lógico” buscar a preservação da própria vida.

\subsubsection{Abordagem discursiva do Texto 3}

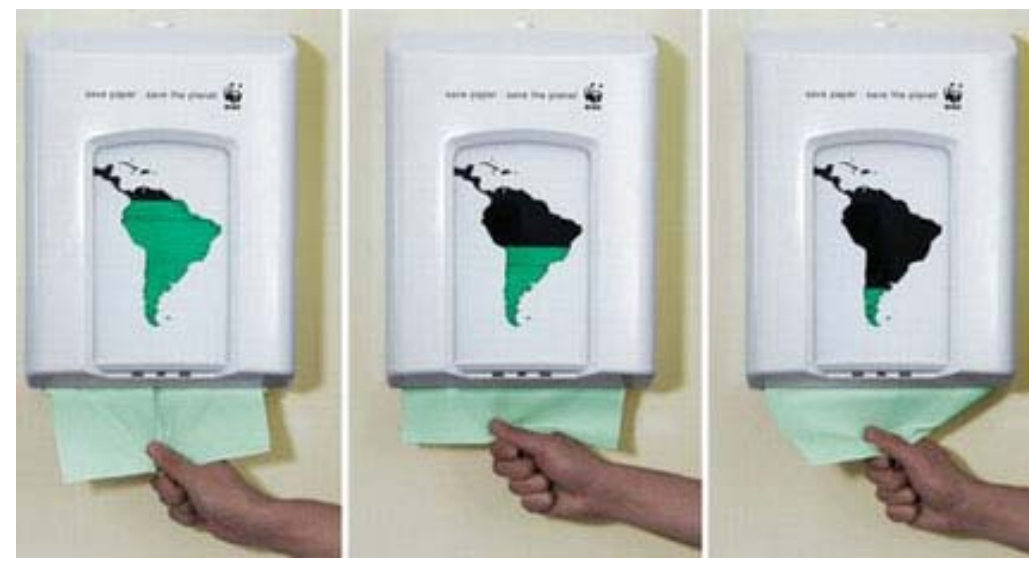

FIGURA 2. Dispenser de banheiro WWF

A imagem acima mostra um dispenser de banheiro criado pela agência de publicidade Saatchi \& Saatchi para a World Wild Foundation (WWF). O dispenser é abastecido com papel-toalha verde e tem uma área transparente com o formato de um mapa da América do Sul. No alto, além do logotipo da WWF, aparece a inscrição: "Save paper, save the planet” ("Economize papel, salve o planeta." ${ }^{8}$ ). A série de fotos captura três momentos: o dispenser quase inteiramente cheio, com metade da capacidade e quase totalmente vazio.

O que se verifica, na integração entre texto verbal e não-verbal, é a suposta existência de uma relação causa/consequência entre "economizar papel" e "salvar o planeta". Mais uma vez se percebe o caráter argumentativo da produção, visto o objetivo claro de conscientizar a população da relação entre o consumo do papel e a derrubada de árvores. Para tal, utiliza-se a mesma estratégia apontada nos textos anteriores: o recurso à ficcionalidade.

Tanto é assim, que, iconicamente, à retirada gradual do papel toalha do dispenser equivale a diminuição do verde no mapa. É, aliás, uma rede metonímica bastante

\footnotetext{
${ }^{8}$ Em português, é difícil preservar o trocadilho baseado na polissemia do verbo inglês “to save”.
} 
interessante: "verde" vale por "floresta"; esta, por sua vez, simboliza o "meio ambiente", que, por fim, referencia o "planeta" como um todo. Não é instantânea a ligação entre a utilização de "uma" folha de papel-toalha e a devastação de florestas. Mais especificamente, o usuário final não é visto como o responsável direto pela queda de nenhuma árvore porque há muitas outras instâncias intermediárias nesse processo: o consumo gera uma demanda; ela justifica a existência de um comércio varejista; este, por sua vez, compra o papel de quem o fabrica tendo obtido a celulose de uma empresa extrativista cujo funcionário (operador de trator ou de motosserra) foi o real agente da derrubada das árvores.

Entretanto, ao lado do conteúdo imagético ali representado, o texto verbal, ao se dirigir ao usuário do papel - marcado gramaticalmente tanto pela desinência número-pessoal de terceira pessoa do singular quanto pelo uso do modo imperativo -, outorga-lhe, também, o poder de, economizando papel, salvar o planeta. A construção desse vínculo causal só é possível graças ao mecanismo da ficcionalidade.

Também faz parte do projeto argumentativo da campanha apelar para uma "lógica autoevidente": o enunciador não precisa se mostrar sincero (não se recorre ao ethos); não é necessário buscar compreender e atender aos anseios do público (dispensa-se a preocupação com o pathos). O discurso convence sozinho (logos), porque é racional proteger o planeta. Como o objetivo é levar as pessoas a não desperdiçarem papel, voltemos à estrutura silogística, sub-repticiamente presente. Vejamos o quadro:

QUADRO 4. Topos "Preservar o planeta é necessário"

[Topos: “Preservar o planeta é necessário.”]

SE “Desperdiçar o papel é destruir o planeta.” (imagem ficcional, argumento utilizado) ENTÃO “Não desperdiçarei o papel.” (conclusão quase-lógica desejada)

Em suma, dar aos argumentos uma feição lógica aumenta-lhes o poder de convicção. "Realidades” são construídas a partir do ponto de vista de quem argumenta, e o sucesso do projeto de persuasão está diretamente relacionado à sua habilidade em articular ideias e modelos estabilizados, colocando-os a serviço da demonstração de teses pessoais a serem assumidas como evidentes. É, por fim, a manifestação da instância discursiva da linguagem.

\section{POR TRÁS DO DISCURSO: A “COGNIÇÃO DOS BASTIDORES”}

Vimos que o efeito persuasivo dos textos estudados pode ser tratado a partir das noções de ficcionalidade e logos. Verificamos que os três textos se fundamentam no logos, uma vez que chamam atenção para a própria lógica interna do argumento. E, mais do que isso, constatamos que a evidenciação dessa lógica se baseia em um mecanismo de construção de mundos ficcionais. Através da evocação desses mundos, os textos se propõem a revelar, para o leitor, a plausibilidade intrínseca do argumento. Por meio desse movimento, o argumento parece capaz de convencer "por si mesmo", quer dizer, pela sua racionalidade inerente. 
Acreditamos que essa seja uma análise bastante razoável sob uma perspectiva discursiva. A mudança para um olhar cognitivista altera o enquadramento do problema, colocando em pauta outras questões. Deve-se ter presente, a partir de agora, que o convencimento é uma experiência subjetiva, vale dizer, uma sensação. E, por mais que um determinado argumento seja coerente, consistente e lógico, nem sempre é simples levar o leitor/ouvinte a experimentar a sensação de perceber-se convencido. Nos textos estudados, essa sensação está associada à ficcionalização. Esta é uma descoberta importante, por instigar outras questões. Primeiro: de que maneira, precisamente, os mundos ficcionais são mentalmente construídos? E, sobretudo: por que, e exatamente como, a criação desses mundos aumenta a eficácia argumentativa de um texto, de modo a conduzir o leitor à experiência subjetiva de convencimento?

Tomando-se, agora, a LC como posto de observação privilegiado, assume-se que o estímulo visual ou auditivo preside à operação de mecanismos cognitivos inconscientes, responsáveis pela construção do significado. Sob esse ponto de vista, a tarefa passa a ser a de desvendar as operações mentais invisíveis que, por se ocultarem por trás das manifestações linguístico-discursivas, têm sido chamadas de "cognição de bastidores" (backstage cognition) (FAUCONNIER; TURNER, 2002).

A principal hipótese desta segunda parte é a de que a operação mental invisível que subjaz à construção do sentido nos textos estudados - e, portanto, ao efeito retórico observado - é o processo conhecido na literatura como mesclagem ou integração conceptual (GRADY; OAKLEY; COULSON, 1999; FAUCONNIER; TURNER, 2002; FAUCONNIER; TURNER, 2008; dentre muitos outros). Esse processo, que tem sido reconhecido como uma operação imaginativa, ao mesmo tempo poderosa e inconsciente, permite projetar elementos de cenários distintos em um único cenário, criando mentalmente, a partir dessa fusão, um mundo alternativo. Isso não significa, a despeito do que essa descrição sumária pode sugerir, que a mesclagem seja atributo exclusivo da imaginação artística. Pelo contrário: trata-se do modus operandi básico do pensamento ordinário, responsável, segundo se tem alegado, por conquistas evolutivas tão profundas quanto o raciocínio matemático (NUÑEZ, 2004) e a própria linguagem humana (FAUCONNIER; TURNER, 2008).

Como notam Fauconnier e Turner (2002), pioneiros no estudo da mesclagem, esse mecanismo é capaz de produzir um tipo de experiência subjetiva conhecido como insight global. Trata-se da sensação de súbita apreensão e compreensão profunda de um determinado conteúdo. Fala-se em insight porque essa compreensão não se dá a partir de uma construção gradual do entendimento; pelo contrário, a sensação é a de uma percepção instantânea. Ao mesmo tempo, esse insight é global porque não envolve o entendimento concatenado de cada parte componente de um dado problema; entende-se o todo de uma única vez, e não suas partes logicamente encadeadas.

Um exemplo esclarecedor desse modo de raciocínio é o caso do monge budista, um enigma proposto pelo escritor Arthur Koestler no livro The act of creation $\mathrm{e}$ reproduzido em Fauconnier e Turner (2002, cap. 3). O enigma pede que o leitor pense em um monge budista que começa a subir uma montanha de madrugada e chega ao topo no pôr-do-sol. Ele medita por alguns dias até que, numa madrugada, decide descer, atingindo o sopé da montanha no pôr-do-sol. Eis a questão: existe algum ponto pelo 
qual o monge passa exatamente na mesma hora em ambos os percursos (a subida e a descida)?

A resposta é “sim”, mas ela talvez não seja imediatamente óbvia. A solução só se torna evidente quando o leitor faz o seguinte exercício mental: imaginar que o monge corresponde, na verdade, a duas pessoas diferentes, que fazem percursos inversos e atingem seus respectivos destinos ao mesmo tempo. Agora, parece evidente que esses dois monges irão se encontrar em algum ponto - e isso resolve o mistério. Esse "ponto de encontro" será, precisamente, o local que o monge da história original ocupará, no mesmo horário, em suas duas travessias separadas pelos dias de meditação.

Eis o que importa enfatizar: a partir do momento em que o leitor constrói imaginativamente esse cenário fictício, com dois monges e duas jornadas num único dia, a solução parece se tornar automaticamente evidente. Isso ocorre porque elementos distintos foram comprimidos em um único todo coerente. Essa compressão conceptual parece facilitar o processamento da informação, levando então à solução imediata, quase instantânea, do enigma. É nesse instante que se dá o insight global, e o leitor experimenta a sensação íntima de ter efetivamente assimilado o problema.

Intuitivamente, o caso do monge budista envolve uma situação de fusão de cenários: a subida e a descida acontecem com alguns dias de diferença, mas nós as imaginamos (i) simultâneas e (ii) levadas a cabo por duas pessoas diferentes. É precisamente por conta dessa fusão que esse processo cognitivo tem sido chamado de integração ou mesclagem conceptual. Convencionalmente, essa operação mental é representada da seguinte maneira:

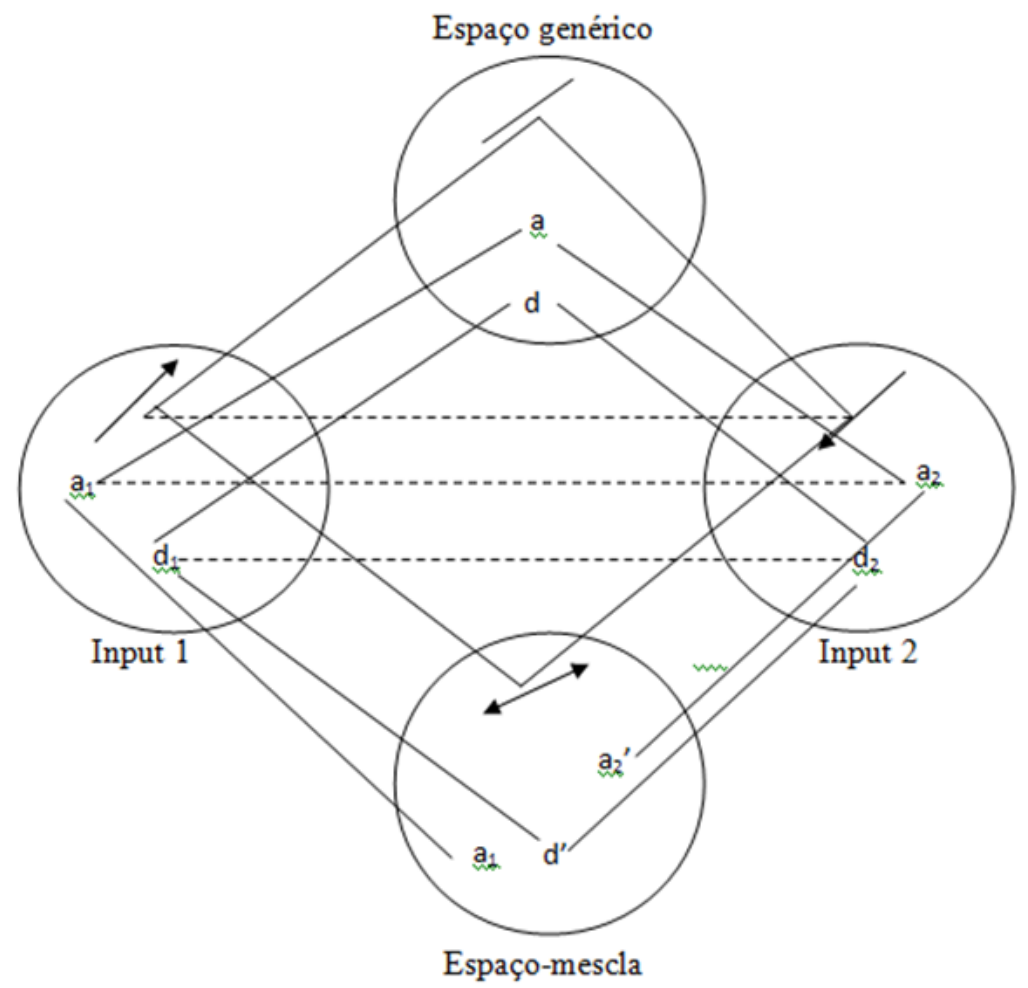

FIGURA 3. Esquema geral da mesclagem conceptual 
No esquema, cada input representa uma das viagens (subida e descida). O trajeto é representado pela linha inclinada, o viajante é representado por $\mathrm{a}_{1} \mathrm{e} \mathrm{a}_{2}$, a direção do percurso é dada pela seta e as marcações $d_{1}$ e $d_{2}$ captam o fato de que as viagens aconteceram em dias diferentes. Esses elementos percebidos como análogos são mentalmente associados: os “dois” viajantes, as duas direções percorridas (para cima e para baixo), as duas datas e a montanha. Tecnicamente, diríamos que se trata de mapeamento mental responsável por conectar as contrapartes ${ }^{9}$.

Neste ponto, é importante sublinhar o fato de que os inputs são espaços fugazes de processamento online de informação; atuam, portanto, no nível da memória de trabalho. Tais espaços devem, assim, ser alimentados pelo "conhecimento de mundo" armazenado na memória semântica. De acordo com a teoria cognitivista, esse conhecimento é representado em estruturas conceptuais denominadas Modelos Cognitivos Idealizados (MCIs).

Para que se estabeleça a associação entre as contrapartes dos inputs, será preciso que eles sejam percebidos, em alguma medida, como instanciações de uma mesma estrutura global. Esse fato é captado pelo espaço genérico, que especifica essa estrutura comum. No exemplo do monge, esse espaço deverá incluir o movimento individual e o percurso inespecificado (para cima ou para baixo, representado pelas flechas duplas), ao mesmo tempo em que exclui aqueles aspectos que diferenciam os inputs (como a direção do trajeto).

Mas a grande inovação da teoria reside mesmo no espaço-mescla, a estrutura para onde são projetados os elementos dos inputs. Os dias $\mathrm{d}_{1}$ e $\mathrm{d}_{2}$, depois de serem conectados, são comprimidos em um único dia d'. Por outro lado, os movimentos de cada travessia original e suas respectivas posições são preservados no que tange aos horários e às direções.

O grande salto imaginativo se opera no espaço-mescla, quando a fusão de cenários distintos produz uma realidade ficcional, da qual o pensamento se beneficia largamente. No exemplo do monge, apenas por meio dessa fusão é que passamos a considerar evidente a resposta da charada. O mais interessante, porém, é que ela dá margem ao aparecimento de elementos conceptuais que não estão presentes em nenhum dos dois inputs - a chamada estrutura emergente. Graças a essa sequência de eventos mentais, emerge um frame novo, ainda que familiar: duas pessoas percorrendo o mesmo caminho em sentidos opostos.

Sustentamos que, nos textos analisados, ocorre exatamente o mesmo processo de mesclagem. Naqueles casos, porém, o interesse reside na constatação de que esse processo produz, como efeito de sentido, um aumento da eficácia argumentativa dos textos. Fundamentalmente, isso ocorre porque a mesclagem promove compressão conceptual, o que, por seu turno, conduz à sensação de insight global.

\footnotetext{
${ }^{9}$ Em uma representação completa, haveria setas ligando diretamente as contrapartes de cada input. No entanto, é praxe, nos trabalhos cognitivistas, que essa representação seja suprimida do esquema, em nome da clareza visual.
} 
Outros estudos - como Coulson (2008; 2006; 2003) e Couson e Pascual (2006) - já chamaram a atenção para a função retórica do processo de mesclagem conceptual. Esses trabalhos, no entanto, enfatizam o papel da mesclagem na manipulação do conhecimento enciclopédico estável (memória semântica) a fim de adaptá-lo e ajustá-lo às necessidades comunicativas mais contingentes. Aqui, por outro lado, estamos focalizando a compressão conceptual promovida pela mesclagem e o efeito gerado sobre o interlocutor: a sensação de insight global, responsável, conforme argumentaremos na próxima seção, pela eficácia argumentativa dos textos selecionados.

Neste ponto, os dois caminhos percorridos neste artigo - a via discursiva e a cognitivista - se cruzam, da seguinte maneira: a sensação de insight global é a contraparte cognitiva da estratégia retórica baseada no logos. É precisamente este o efeito da mesclagem, responsável pela sensação de insight: fornecer ao leitor a experiência subjetiva de estar diante de um argumento cuja lógica interna parece autoevidente.

\subsection{Abordagem cognitivista dos textos: a engrenagem mental da ficcionalização}

\subsubsection{Abordagem cognitivista do Texto 1}

Parece claro que o texto da neurocientista Suzana Herculano-Houzel conduz a um insight global. A autora chega a explicitar esse recurso retórico, ao observar que, para convencer os alunos, procura-se criar uma "imagem-suficientemente-impactante-parafazer-mudar-de-ideia”. Essa imagem, por ser gerada via mesclagem, permite a apreensão instantânea do problema. Até então, os alunos pareciam não ter assimilado a ideia de que descer ao laboratório "mascando chiclete, comendo, bebendo água ou com bala na boca" era algo reprovável. No entanto, a partir do momento em que eles chegam à imagem mesclada descrita ao final do texto - "lamber as peças e os cadáveres da aula" - isso parece não só razoável, mas natural e autoevidente. Dessa maneira, o processo argumentativo se completa.

A operação de integração conceptual executada é representada na Figura $4^{10}$ :

\footnotetext{
${ }^{10}$ Novamente, não representamos os links de identificação entre as contrapartes dos inputs. Além disso, mais uma vez, seguindo a praxe dos estudos cognitivistas, não explicitamos aqui o espaço genérico, uma vez que ele não é diretamente relevante para a análise. Por fim, em nome da clareza visual, indicamos os MCIs acima de cada espaço input - onde normalmente estariam os rótulos “input 1", "input 2" e "input 3" - e não abaixo, como é usual.
} 


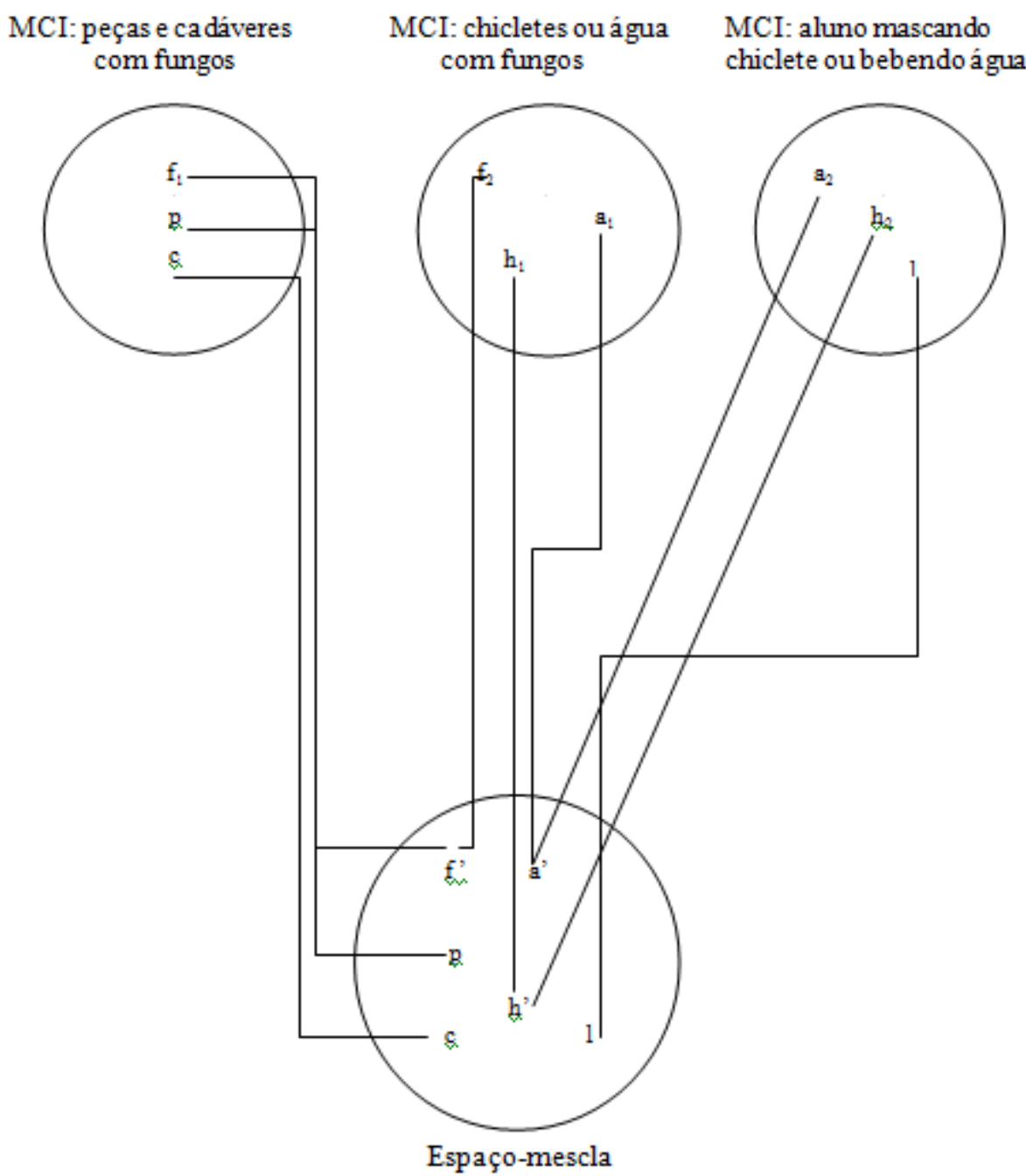

FIGURA 4. Processo de mesclagem do Texto 1.

O primeiro espaço mental exibe um cenário em que peças anatômicas e peças fixadas em cadáveres contêm fungos. O segundo espaço mental representa elementos chicletes ou água cuja superfície está coberta de fungos. O terceiro espaço, por sua vez, representa uma cena trivial: alunos mascando chicletes ou bebendo água. Tomados individualmente, os três cenários parecem bastante naturais e, mesmo, banais.

No entanto, como previsto pelo modelo, o espaço-mescla irá produzir aquilo que se tem chamado de estrutura emergente, ou seja, um conteúdo conceptual novo, que não comparece em nenhum dos três inputs: aqui, esse conteúdo inclui o contato direto entre a língua dos estudantes e os cadáveres.

A estrutura emergente decorre naturalmente da configuração resultante do espaçomescla. Do input 1, são projetadas diretamente as peças anatômicas e os cadáveres; do input 3, são projetados diretamente os alunos. Os elementos referenciais representados em mais de um espaço - fungos, água e chiclete - são unidos por um link de identificação, de maneira que duas representações conceptuais distintas são fundidas em uma única representação. Dessa forma, o falante assume que se trata dos mesmos fungos, da mesma água e do mesmo chiclete. 
Como resultado, o espaço-mescla irá conter seis elementos: peças, cadávares, chiclete, água, fungos e alunos. Dado que os fungos relacionados às peças/cadávares e a chiclete/água são percebidos como os mesmos (já que foram associados por meio dos mecanismos presentes na operação de mesclagem), o ouvinte irá inferir que a língua do aluno está em contato direto com os próprios cadáveres ou com as peças anatômicas. Em outras palavras, a ideia de que as pessoas estão lambendo cadávares perfaz a estrutura emergente da mesclagem, que, como dissemos, é inferência decorrente da configuração final do espaço-mescla.

Note-se o poder argumentativo da estrutura emergente: é ela que corresponde à "imagem-suficientemente-impactante" de que fala a neurocientista. É essa imagem presente na estrutura emergente que, em última instância, é capaz de persuadir. Como a ideia está incluída no espaço-mescla - uma gestalt internamente coerente resultado de compressão conceptual - ela produz a sensação de um insight global. E, graças a ele, ao insight, o conteúdo expresso pelo argumento parece autoevidente e, consequentemente, irrefutável: é a ação do logos.

Gostaríamos de mostrar que o mesmo mecanismo está em jogo nos outros dois textos argumentativos que analisamos. Comecemos com o texto que tematiza a campanha pela disseminação do teste de HIV.

\subsubsection{Abordagem cognitivista do Texto 2}

No Texto 2, de maneira bastante análoga ao que ocorre no Texto 1, o objetivo é conscientizar o leitor de riscos - agora inerentes à relação sexual - e, a partir daí, levá-lo a fazer o teste de HIV. Aqui, diversas relações afastadas no tempo e no espaço são comprimidas num único frame espaço-temporal. O espaço genérico é, portanto, o de relação sexual, e os diversos inputs (no esquema abaixo, I1, I2 e I3) - e, neste caso, pode-se supor uma série potencialmente infinita de inputs - exibem uma relação específica. Em cada um deles, a mulher é a mesma, mas os homens são diferentes. Todos esses homens, contudo, são conceptualmente identificados e projetados, juntos, no espaço-mescla, o que transparece na imagem. Como resultado, o espaço-mescla representa uma relação com múltiplos parceiros ${ }^{11}$.

\footnotetext{
${ }^{11}$ Não iremos discutir aqui a interferência, na mesclagem, do processamento metonímico (os parceiros antigos, ao contrário do atual, são representados apenas por seus braços).
} 


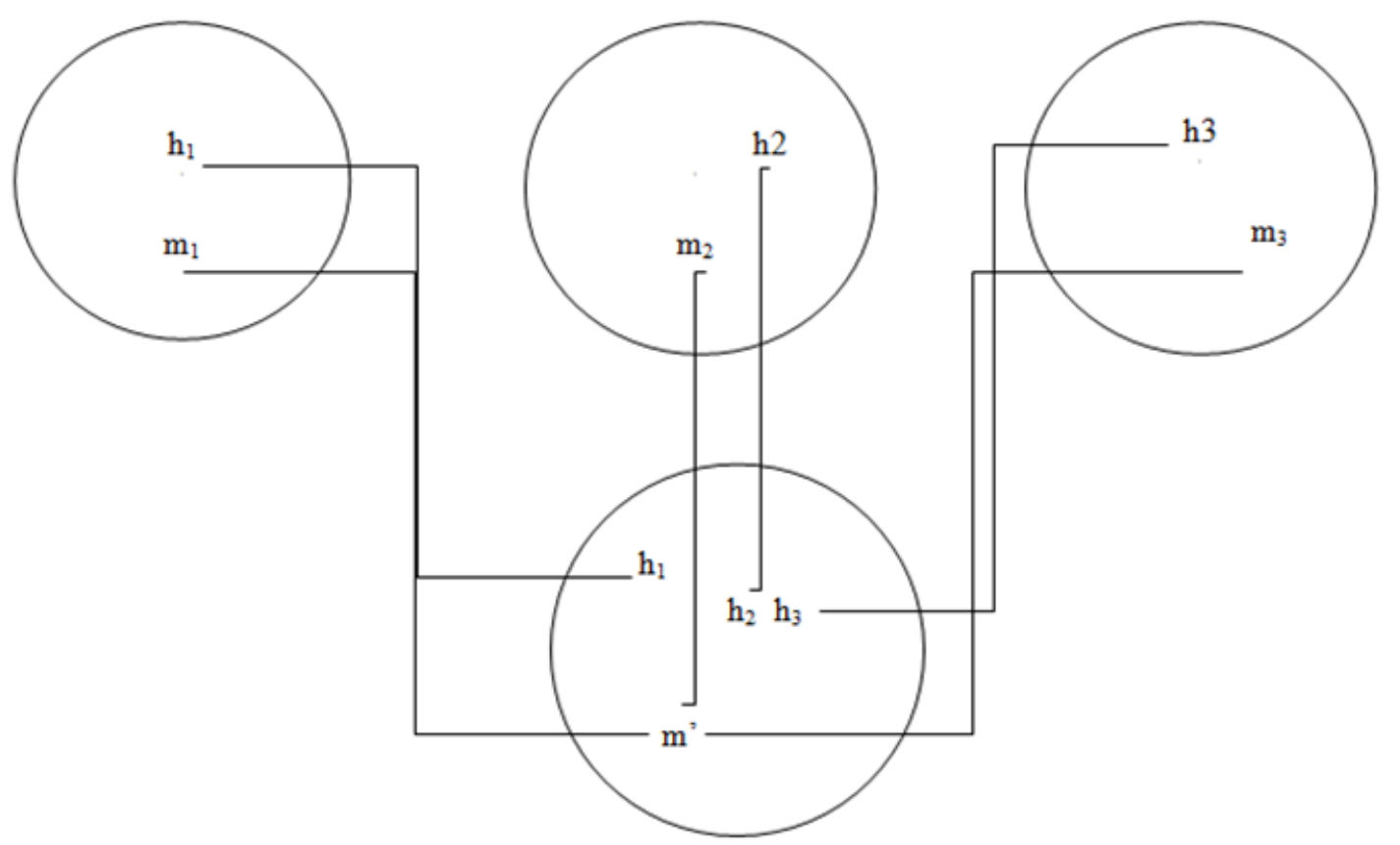

FIGURA 5. Processo de mesclagem do Texto 2.

Mais uma vez, neste caso, é a inferência gerada a partir do espaço-mescla que torna o argumento eficaz e produz a sensação de convencimento, a partir da produção de um insight global.

Eis o raciocínio. É possível que alguém subestime os riscos à saúde provocados pelas relações sexuais quando esses riscos são indiretos, envolvendo transmissões encadeadas, de um parceiro para o outro, deste para o seguinte, e assim sucessivamente. Em poucas palavras, é fácil esquecer que pessoas desconhecidas, com que não se tem contato, também oferecem riscos. No entanto, a partir do momento em que esses desconhecidos se tornam pessoas próximas, com as quais há um contato direto, fica bem mais difícil ignorar os riscos oferecidos por elas. Isso, porém, só ocorre no espaçomescla, atingido imaginativamente. É, portanto, a partir do cenário ficcional construído nesse espaço que o ponto do argumento é realçado, tornando o texto persuasivo.

\subsubsection{Abordagem cognitivista do Texto 3}

No dispenser da World Wild Foundation, retratado pela imagem que constitui o Texto 3 , a estratégia empregada para levar o consumidor a economizar papel consiste em fazer o usuário se sentir o responsável direto pelo desmatamento. Esse efeito, porém, só pode ser produzido graças a um mecanismo complexo de mesclagem.

Não iremos repetir aqui a interpretação da imagem já descrita na seção anterior, que envolve a decodificação de uma série de metonímias. O objetivo é evidenciar, também nesse terceiro exemplo, o papel argumentativo da compressão promovida pela mesclagem. Na figura 3, essa compressão atua sobre aquela cadeia de eventos causais 
descrita em linhas gerais na seção 2.2 - uma cadeia que, como se viu, começa no consumidor do papel e irá culminar na derrubada de árvores.

Para interpretar a figura 3, é preciso comprimir toda essa cadeia causal de modo a manter apenas seus extremos: o uso de papel pelo consumidor final e o desmatamento. Quando se olha a figura 3 - ou quando alguém usa, na prática, o dispenser, no interior de um banheiro público - todas as instâncias intermediárias desaparecem. Com isso, uma sequência complexa de eventos é transformada em uma cena agentiva prototípica, na qual um único indivíduo exerce uma força sobre um objeto, alterando sua composição. Se na cadeia causal a responsabilidade pelo evento final é diluída, na cena agentiva prototípica ela recai toda, claro, sobre o agente único.

Nesse sentido, cada um dos inputs da mesclagem corresponde a uma etapa da cadeia causal. De um lado, está o momento inicial, em que o usuário consome o papel; de outro, o momento final, em que o funcionário da empresa extrativista efetivamente derruba as árvores. É fácil notar que existe, como prevê o modelo, uma estrutura comum entre esses dois inputs: ambos são instâncias de uma cena agentiva arquetípica. Essa cena, representada no EG, licencia o estabelecimento de uma relação analógica entre o usuário do produto e o funcionário da empresa extrativista (digamos, o tratorista), com base no fato de que ambos desempenham o papel de agente.

Estabelecida a relação analógica entre esses dois agentes, está pavimentado o terreno para que eles sejam projetados e fundidos no EM. Dessa forma, surge um agente mesclado: ao mesmo tempo, consumidor e tratorista. De fato, o que vemos, ao observar a cena (apenas aparentemente banal) de um cliente usando o dispenser, é alguém que, simultaneamente, consome papel e derruba árvores (metonimicamente representadas no dispenser, como vimos, por dois componentes do papel: a cor - verde - e matéria-prima - celulose).

O mesmo acontece com o tema das cenas agentivas: no input 1, o papel; no input 2, as árvores. Licenciada pelo esquema imagético que alimenta o EG, a relação analógica entre eles permite projetá-los no EM e comprimi-los em um único elemento. $\mathrm{O}$ estabelecimento de uma relação analógica entre esses dois agentes é o que permite que todos eles sejam comprimidos no espaço-mescla. Como a cena efetivamente exibida pela figura 3 tem como agente apenas o consumidor final, é ele que representa ou materializa, na prática, esse agente mesclado.

Por outro lado, e esse parece ser o grande truque desta mesclagem, o mesmo processo de compressão não ocorre com o outro componente da cena agentiva, o tema. Se o agente do EM é o resultado da fusão de dois dos agentes da cadeia causal, o único tema projetado no EM, por outro lado, é a árvore. Desse modo, constrói-se a ideia de que ambos os agentes atuam, ao fim e ao cabo, sobre uma única "vítima” final: a árvore, metonicamente representada no dispenser (como vimos) pelo verde que cobre o mapa da América do Sul.

A Figura 6 sintetiza os processos descritos. 


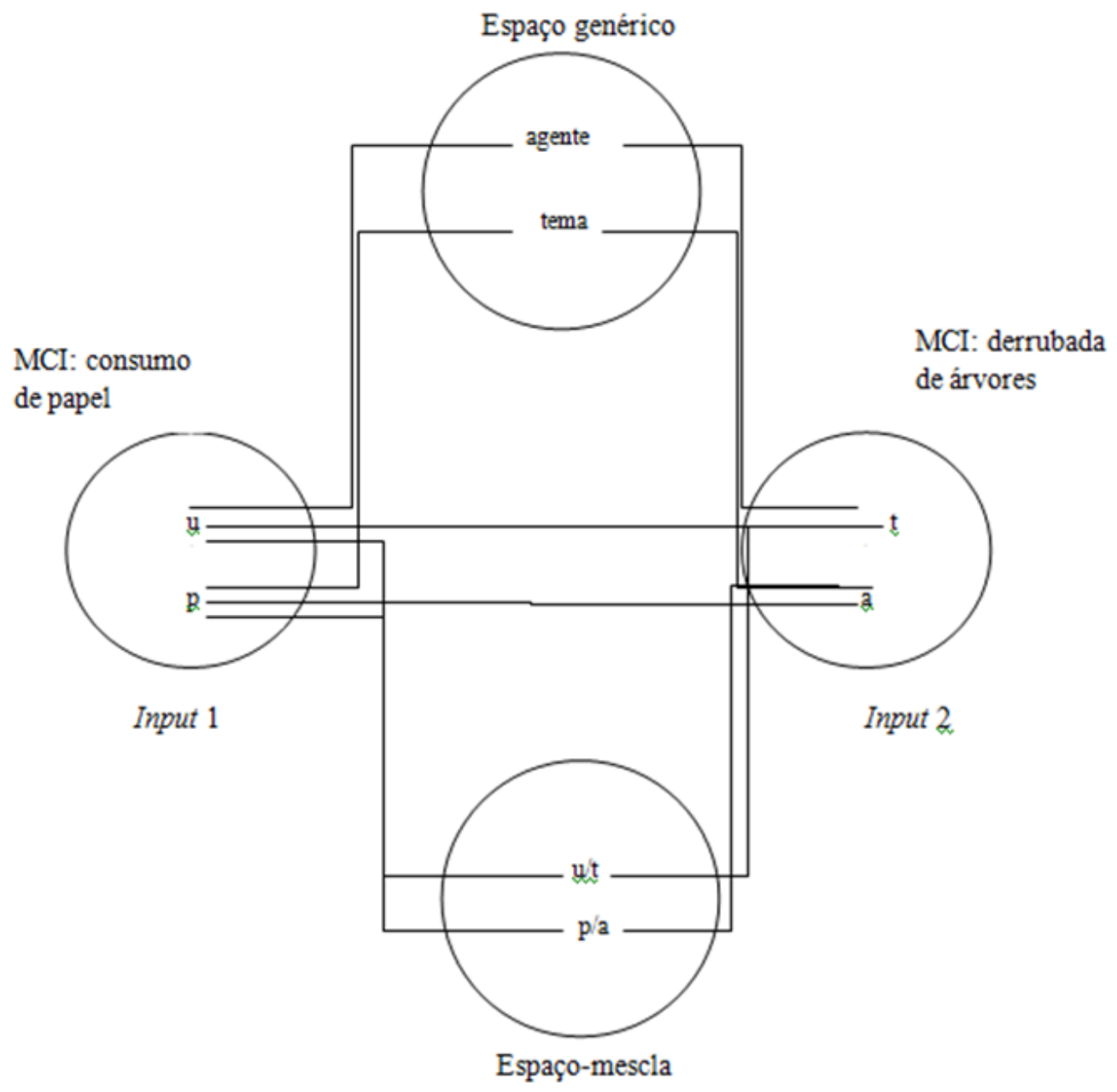

FIGURA 6. Processo de mesclagem do Texto 3.

Em resumo, a análise dos três textos aqui desenvolvida sob perspectiva cognitivista comprova a hipótese inicial: é possível, como procuramos demonstrar, descrever a construção da ficcionalidade como resultado da compressão promovida pela mesclagem conceptual. A tabela abaixo ajuda a visualizar as analogias entre os três textos analisados:

TABELA 1. Síntese comparativa da mesclagem nos três textos

\begin{tabular}{c|l|l}
\cline { 2 - 3 } & \multicolumn{1}{|c}{$\begin{array}{c}\text { Operação de } \\
\text { compressão realizada }\end{array}$} & Estrutura emergente produzida \\
\hline Texto 1 & $\begin{array}{l}\text { Fungos distintos se tornam entidades } \\
\text { únicas. Diferentes cenas se fundem em } \\
\text { um único cenário. }\end{array}$ & $\begin{array}{l}\text { Alunos em contato direto com } \\
\text { cadáveres }\end{array}$ \\
\hline Texto 2 & $\begin{array}{l}\text { Diferentes tempos e espaços se fundem } \\
\text { em um único cenário. }\end{array}$ & \multicolumn{1}{c}{$\begin{array}{c}\text { Relação com múltiplos } \\
\text { parceiros. }\end{array}$} \\
\hline Texto 3 & $\begin{array}{l}\text { Diferentes tempos, espaços, agentes e } \\
\text { temas se fundem em um único cenário. }\end{array}$ & $\begin{array}{l}\text { Usuário do papel causa } \\
\text { diretamente o desmatamento }\end{array}$ \\
\hline
\end{tabular}




\section{4 ÚLTIMAS PALAVRAS}

Como vimos, o processo de convicção por logos pode esconder muitos artifícios por detrás de sua aparente clareza. A persuasão nem sempre se dá pela racionalidade intrínseca das ideias; também se argumenta por meio de uma engenhosa articulação de realidades possíveis, ficcionais, cuja (re)construção só acontece pelo fato de nossas mentes serem capazes de fundir, numa só, cenas (espaços) diferentes.

Neste artigo, em suma, procuramos sustentar que (i) o mecanismo discursivo de ficcionalização contribui para o projeto argumentativo, e (ii) o mecanismo cognitivo subjacente à ficcionalização é a mesclagem conceptual, cuja capacidade de promover compressão conceptual é a responsável direta pelo insight global, que produz a sensação de convencimento.

Acreditamos, por fim, que nossa opção por uma análise interdisciplinar, aliando AD e LC, tenha se justificado: essa seria, a nosso ver, um caminho natural a fim de traçar o percurso mente $\mathrm{X}$ língua $\mathrm{X}$ discurso. Assim, a habilidade cognitiva de (re)criar a realidade - a mescla - possibilita o mecanismo de ficcionalização, e este, nos casos apresentados, viabiliza a argumentação por logos.

\section{REFERÊNCIAS}

AMOSSY, R. (Org.). Imagens de si no discurso, a construção do ethos. São Paulo: Contexto, 2005.

ARISTÓTELES. Arte retórica e arte poética. Rio de Janeiro: Ediouro, 2005.

CHARAUDEAU, P. Linguagem e discurso - modos de organização. São Paulo: Contexto, 2008.

CHARAUDEAU, P.; MAINGUENEAU, D. Dicionário de Análise do Discurso. São Paulo: Contexto, 2008.

CHARAUDEAU, P. Uma análise semiolinguística do texto e do discurso. In: PAULIUKONIS, M. A. L.; GAVAZZI, S. (Orgs.). Da língua ao discurso - reflexões para o ensino. Rio de Janeiro: Ed. Lucerna, 2005.

COULSON, S. Framing and blending in persuasive discourse. In: FAVRETTI, R. R. (Ed.). Frames, Corpora, and Knowledge Representation. Bologna: Bononia University Press, p. 33-42, 2008.

Conceptual Blending in Thought, Rhetoric, and Ideology. In: KRISTIANSEN, G.; DIRVEN. R. (Eds.). Cognitive Linguistics: Current Applications and Future Perspectives. Amsterdam: John Benjamins, p. 187-210, 2006. 
Reasoning and rhetoric: Conceptual blending in political and religious rhetoric. In: OLESKY, E. H.; LEWANDOWSKA-TOMASZCZYK, B. (Eds.). Research and Scholarship in Integration Processes. Lodz, Poland: Lodz University Press, p. 59-88, 2003.

; PASCUAL, E. For the sake of argument: Mourning the unborn and reviving the dead through conceptual blending. Annual Review of Cognitive Linguistics 4: 153-181, 2006.

CROFT, $W$. The role of domains in the interpretation of metaphors and metonymies. In: Cognitive Linguistics 4, 335-370. Berlin/New York: Mouton de Gruyter, 1993.

FAUCONNIER, G.; TURNER, M. The way we think. New York: Basic Books, 2002.

FAUCONNIER, G.; TURNER, M. Rethinking Metaphor. In: GIBBS, R. (Ed). Cambridge Handbook of Metaphor and Thought. Cambridge: Cambridge University Press, 2008.

FAUCONNIER, G.; TURNER; M. The origin of language as a product of the evolution of modern cognition. In: LAKS, B. (Ed.). The origins and evolution of languages. London: Equinox Publishers, 2008.

GRADY, J.; OAKLEY, T.; COULSON, S. Conceptual Blending and Metaphor. In: GIBBS, R. (Ed.). Metaphor in Cognitive Linguistics. Amsterdam/Philadelphia: John Benjamins, 1999.

LAKOFF, G.; JOHNSON, M. Philosophy in the flesh: the embodied mind and its challenge to Western Thought. New York: Basic Books, 1999.

LAKOFF, G.; JOHNSON, M. Metaphors we live by. Chicago: The University of Chicago Press, 1980.

MENDES-LOPES, E. O discurso ficcional: uma tentativa de definição. $134 \mathrm{f}$. Dissertação de Mestrado em Estudos Linguísticos. FALE/ UFMG, Belo Horizonte, 2000.

MENDES-LOPES, E. Contribuições ao estudo do conceito de ficcionalidade e de suas configurações discursivas. 267 f. Tese de Doutorado em Estudos Linguísticos. FALE/ UFMG, Belo Horizonte, 2004.

MENDES-LOPES, E. O conceito de ficcionalidade e sua relação com a Teoria Semiolinguística. In: MACHADO, I. L. et al. (Orgs.). Movimentos de um percurso em Análise do Discurso. Belo Horizonte: FALE/ UFMG, 2005.

NUÑEZ, R. Do real numbers really move? Language, thought, and gesture: The embodied cognitive foundations of mathematics. In: IIDA, F.; PFEIFER, R.; STEELS, L.; KUNIYOSHI, Y. (Eds.). Embodied Artificial Intelligence. Springer: Berlin, 2004. 
PERELMAN, C.; OLBRECHTS-TYTECA, L. Tratado da argumentação - a nova retórica. São Paulo: Martins Fontes, 1996.

REBOUL, A. Rhétorique et stylistique de la fiction. Nancy: Presses Universitaires de Nancy, 1992.

REBOUL, O. Introdução à retórica. São Paulo: Martins Fontes, 2004.

\section{ANEXO}

\section{Uma imagem suficientemente ruim na cabeça}

O pessoal do Fantástico me pediu para comentar o caso da menina de cinco anos que ficou sozinha em casa, caiu da janela e morreu. Acho que a mãe dessa criança já vai amargar a (ir)responsabilidade pela morte da filha pelo resto da vida e não estou aqui para julgar ninguém. Mas vamos ao básico:

Sim, crianças de 5 anos têm medo de várias coisas, inclusive de altura, mas não, crianças de 5 anos não sabem antecipar desgraças. Seu córtex pré-frontal ainda não é maduro suficiente, nem tem experiência suficiente, para saber que tipo de coisa leva à outra quando menos se espera. Já o cérebro de uma pessoa adulta, com o córtex órbitofrontal maduro e já craque em antecipar arrependimentos, deveria ser perfeitamente capaz de antecipar o potencial de catástrofe em deixar uma criança sozinha. Por isso é que se pressupõe que sempre há um responsável maior de idade (leia-se, portador de um córtex órbito-frontal amadurecido) em casa onde tem crianças brincando. Por isso o responsável é o pai e a mãe, e não a criança.

Mas é possível ajudar a criança a não fazer besteira. Antecipar catástrofes em potencial para elas é uma excelente maneira de ir educando desde cedo seu córtex pré-frontal mas isso tem que ser feito com sensatez e parcimônia: se qualquer pequena besteira for ameaçada com um "assim você vai parar no hospital!", a frase perde a força. Lá em casa temos avisos de vários tipos, de "assim você vai bater a cabeça na mesa" (geralmente seguida por uma cabeçada na mesa, de fato - o que tem sua função, porque eles acabam confiando nas nossas previsões!) ao inevitável "não quero ter que sair correndo agora para o hospital", passando pelo "essa brincadeira dá dente quebrado" e coisas do gênero.

Mas quando a coisa se anuncia realmente perigosa, uma imagem especialmente nefasta ajuda a manter as crianças seguras. Os bancos da cozinha *jamais* são levados para a área, onde a janela é grande e costuma ficar aberta. As crianças sabem por que os bancos não podem ir para lá: porque, se eles escorregarem e cairem pela janela, eles morrem - e eu vou chorar o resto da vida. Como eu não sou de dizer isso o tempo todo, eles ficam de olhos arregalados e a coisa funciona.

E depois, tem a versão light da imagem-suficientemente-impactante-para-fazer-mudarde-ideia. Minha estagiária Bianca lembrou esta semana da minha estratégia com os alunos da Psicologia para que eles não descessem ao Anatômico, onde têm aulas práticas, mascando chiclete, comendo, bebendo água ou com bala na boca. Saca só a lógica: as peças anatômicas, mesmo as plastinadas e super bem cuidadas, têm fungos na 
superfície, e esses fungos passeiam pelo ar e são adsorvidos pela bala, chiclete ou água na sua boca. O mesmo vale para as peças fixadas, que exalam formol. Portanto, se fungos e formol são adsorvidos pelo chiclete, descer para a aula prática mascando chiclete é o mesmo que... lamber as peças e os cadáveres da aula. Você faria isso?

Eu também não. Pelo jeito, parece que a coisa funciona: eu não preciso avisar duas vezes, e Bianca ainda lembra do aviso três anos depois. Agora só falta descobrir qual é o truque para fazer com que os alunos usem o jaleco...

(Disponível em: http://www.suzanaherculanohouzel.com. Acesso em: 27/11/09) 